\title{
Lisa Pohlmann
}

\section{INTRODUCTION}

Women's organizations are a crucial vehicle for articulating women's experience, needs, and priorities. Their role in setting agendas and mobilizing support, implementing programmes for women and agitating for change has gained increasing recognition. Throughout the world, women's organizations have questioned traditional leadership roles and organizational practices which have served to marginalize the women who work in them and the women they serve. They have experimented with different internal structures and behaviours with an intention to develop more equitable distributions of power and decision making.

In a developing country like Bangladesh, women's organizational efforts take place in a competitive development community where resources are scarce and information is guarded. Attracting and securing the support of international donors requires ongoing energy and, often, compromise. Addressing the survival needs of women must be balanced with ideological debate, programme experimentation, and national policy advocacy. The alternative approaches to women's empowerment promoted by women's organizations are usually met with resistance by their male counterparts who dominate the policy making arena. Women leading small grassroots and activist organizations are faced with a daunting task, yet their innovations in organizational structure and programme strategy have served as models for the directions in which 'women in development' must go, and bear ongoing evaluation.

This article is based on a phenomenological study conducted in 1993-4 exploring the experience of

\footnotetext{
1 This paper is taken from a thesis in progress entitled, 'A Phenomenological Study of Female Leaders and Conflict in Organizations Working on Women's Empowerment in Bangladesh.' The methodology centred on in-depth interviews with the leaders of four women's organisations including two rural development organisations, one project providing urban organizing with garment workers and gender training to NGOs, and one activist networking organisation. The organisations were selected based on their maintenance of a predominantly female
}

today's leaders of women's organizations in Bangladesh. ${ }^{1}$ It focuses on the ambivalence women feel about leadership within and between women's organizations, revealed through the perspective of these leaders, and augmented by my own experience as a leader of a women's organization in the US for ten years.

It is conjectured that the roots of this ambivalence stem from working in the transition period in which new models of authority are being created and practised while traditional models are also being replicated. Additionally, ambivalence stems from operating in the nexus between the new powersharing models within the organization and the hierarchical models that dominate the public sphere where the organization must also work. These will be discussed in terms of conflicts within and external to the individuals and organizations.

\section{AMBIVALENCE}

- a simultaneous desire to do two opposite things;

- the coexistence of positive and negative feelings about the same person, object, or action;

- fluctuation due to the inability to make a choice. ${ }^{2}$

\section{WHAT'S WRONG WITH BEING A LEADER}

Certain skills are needed to create and maintain organizations including coordination, vision, the ability to strategize, and interpersonal group skills to facilitate the adoption of the vision and strategy (Adamson, Briskin, McPhail 1989). Traditionally, these initiatives have fallen to one individual who

staff, executive board, and membership, and their explicitly stated goals of women's empowerment. I thank the following organizations: Nari Progati Shanga (Women's Development Organization), Shaptagram Nari Swanivar Parishad (Seven Villages Women's Self-Reliance Movement), Nari Uddug Kendra (Centre for Women's Initiatives), and Naripokkho (Pro-Women).

2 Definition adapted from Random House College Dictionary, Revised Edition, 1975, Random House. 
remains in a central position. This was the case for three of the women I interviewed who were the ongoing executive directors of their organizations. The fourth organization had an initiator position called the 'convenor' which rotated among the members every few years.

The participants indicated resistance to the term 'leader'.

Frankly speaking ... I cannot say that I am really a leader ... I try to put efforts in what I think is right for women. That drive I have inside me.

I think I would much rather be called an organizer than a leader.

Women's organizations around the globe have been grappling with the concepts of leadership, power, and authority throughout the most recent decades of feminist organizing. ${ }^{3}$ (Mumtaz and Shaheed 1987; Gandhi and Shah 1992, offer examples from the South Asian region.) Male models of authority have been rejected as reinforcers of a system of domination and subordination. Women have opposed bureaucratic norms of hierarchy, top-down communication, and objectivity as incompatible with feminist values of egalitarianism, participation, and connectedness (Ferguson 1984).

However, attempts at removing authority altogether have often led to ineffective internal functioning, so many women's organizations have maintained or returned to centralized leadership and authority while trying to modify its impact. At the same time women's organizational agendas include establishing their collective authority on what defines 'women's' and 'women's interests' in the maledominated areas in which they work

Despite some feminists' aversion to authority the concept cannot be easily abandoned or avoided because it involves 'the question of founding a meaningful common life' in which women must participate to figure out how 'to act rightfully and not just act' (Jones 1993: 7). This applies to both the internal and the public life of women's organizations where the role of leaders as bearers of authority breeds conflicting feelings. Redefining rather than eschewing the concept and practice of authority is essential to the transformative politics women seek.

\section{CONFLICTING MOTIVATIONS ABOUT LEADERSHIP}

Women have real problems accepting that they're leaders. They're always trying to compensate for it somehow. I think it's lack of social confidence partly, and it comes from wanting to share ... Most women have that.

This quote highlights that there are both positive (wanting to share) and negative (lack of confidence) motivations for which women evade a strong identification with leadership. This can be further explored as an example of ambivalence.

The three directors in Bangladesh, like many other directors or women's organizations, indicated that they were not operating in a strict hierarchical operation. Each described their organizations as being in some way a collaboration. Words that were used were 'family,' and 'team spirit'. As far as their own management styles, they said, 'I don't dictate', 'I don't do a sort of bossy top-down management', 'I am a participatory leader', 'It's a cooperative method'. They described working closely with their staff and beneficiaries, respecting their input and facilitating some collective decision making. New structures were being tried; for example, one organization was working towards replacing the position of executive director with a management team.

This propensity for participatory management styles and non-hierarchical approaches has been cited as a feminine attribute in management studies and is increasingly recognized as effective in conflict resolution and staff development as well as overall productivity. In a study on women and management, women described their leadership

feminist, we did not discuss their particular definition of the word. For this reason, I have avoided its use throughout most of this paper. It is mentioned here to indicate that there has been a movement of women who have sought to challenge gender inequity and its manifestations in organizations which is distinguished from the many women's organizations through recent history who have worked on a variety of issues but have not taken such stands. 
styles as including rather than excluding as many people as possible (Chernesky and Bombyk 1988). As administrators, 'Women anticipate, interpret, and respond to the needs of others and thereby are sensitive and empathic ... as well as nurturing and cooperative' (ibid.: 57). The wish to share power, seen here as positive, is also seen as the antithesis of traditional power-mongering in hierarchical organizations. Women would rather see themselves as 'organizers' who share power than 'leaders' with a monopoly on power.

Yet, women still bear the scars of trying to gain power over their lives in a world that systematically denies them access to power. They have been socialized to mistrust themselves to handle authority and to abdicate their power to men, which, in turn, keeps men in power. Shying away from and not competing for power is a self-perpetuating cycle in which women never achieve autonomy. Therefore, their lack of confidence has been something to overcome by claiming leadership and authority in order to gain access to power in a male-dominated world.

\section{TWO WORLDS IN WHICH TO OPERATE}

Since women's organizations operate in an arena still dominated by men, they must also adapt their management styles outside their organizations in order to participate in the public sphere. At the same time that they attempt to step back and share power within their organizations, then they must also be strident, aggressive, and powerful to promote women's agendas and protect their organizational interests in the external world. The interviewees gave these examples of wielding their power among men:

In (one area) there were some local people that wanted financial and other benefits ... They threatened that if they were not obliged, they would see how I could run this organization ... I had to meet the local leaders and ... tell them if they want to (harass us), I have some connections in the government administration and in the police. If they think they have the power to threaten me, I also have some power to tackle those threats ...

Nobody ever provokes me. That's talked about everywhere. I'm the only person they've seen (confront the biggest NGO leaders). Even government officers talk with a certain respect to me ... I can be terribly aggressive and abrasive as a lot of men say. But I can also establish a rapport with people if I want to very easily.

I'm always fighting ... in the work place, in the street, in the buses, at home ... Everybody wants (me to stop being) too much, extreme - to tone a little bit down, wherever I go.

These same women said of their organizational behaviour:

It's very difficult to share power but my whole experience is that you're far more successful sharing power rather than being powerful.

The organization is a family. Everybody has to help each other.

One woman summed up an aspect of this conflict:

I notice with people there are dominating trends developing in women's leadership. This develops due (to the fact) that when we as women come out, we have to fight such adverse situations. To (survive) we have to be very dominating and that may become a usual or inherent part of ourselves. Sometimes it creates some trouble if someone is not very conscious about it.

The energy that women expend to push their way through their own internalized oppression and ongoing male opposition. into the arena of public life can develop into a hardened shell that they may not recognize. Some women who have reached leadership positions carry a shield of arrogance or aggressiveness that may make them difficult to communicate with, even for their colleagues.

The external hierarchical world also undermines attempts to minimize a focal point of leadership. Funding agencies require a single chief with whom to relate, as do the press, governmental bodies, etc. As one woman said,

There's a tendency for outsiders to give recognition only to individuals. When people give this ability to me (to talk about our organization), that invisibilizes a whole process I am part of. I resist that a lot not only because I have difficulties accepting internally this role of leader, but also because I'm opposed to it. It's a 
refusal to see process ... It also makes me upset because it causes problems in my own organization. It creates resentment. 'Why (is she the only one) getting recognized?'

Again, there is a simultaneous desire for women to reject and embrace powerful behaviour in their role as leaders, depending on with whom they are working. Even if consciously chosen and managed, this interferes with an integrated approach to leadership.

\section{FEAR OF DOMINANCE WITHIN THE ORGANIZATION}

Women are motivated by necessity to work together for greater strength and self protection. One woman pondered on this as a difference between women and men's leadership:

Women tend to sit around and discuss things among themselves because they have more enemies outside - men and the society. Because we are the victims, we tend to cooperate together more than men do.

However, an emphasis on being 'victims' may also be carried into women's interactions with each other in organizations where there is supposedly no threat. The fear of domination experienced as part of the victimization process may be projected onto those seen as being powerful. It is particularly difficult to assess whether and how domination is occurring in groups that are practising new forms of non-hierarchical operation. Saheli, a women's organization in Delhi, noted that coordination by an individual can be mistaken for authoritarian behaviour while accountability as well as responsibility is mistaken for hierarchy (Saheli 1985).

Leaders may be resented for this perceived dominance. One woman noted:

An unjustifiable complaint (from my colleagues) was that I dominate. I felt at one point it had become mythology as well. The fact that I don't dominate is not something people were going to open their eyes and see. If people actually analysed decisions and decision making, they would realize that I don't. There were decisions taken that I didn't agree to or that I didn't have anything to do with, or that, if I really dominated, I would make sure were not taken.
This challenge to authority also appears to emerge over time. The above quote came from one of the two women whose organizations had been operating for over 10 years. The other also had a story of resentment toward her authority from inside the organization that brewed into a small-scale rebellion led by one long time worker. These stories were in contrast to the two who had been operating less than ten years who said there had been no internal challenges to their authority.

From my own experience, the atmosphere of a new social change organization is usually one of great support for the leader - an allegiance to shared ideals and a belief that the leader embodies them. However, with time, the ambivalence of each member toward authority has more chance to emerge, especially among women who already fear dominance. This process occurs at different rates, but it was not surprising to see that there was a difference in the 'younger' and 'older' organizations. The same woman quoted above said:

(When I was the only one being recognized by the outside world as the authority on our organization) some resentment spilled over to me so I felt angered by that. I was not very sensitive to their constraints. I just kind of reacted, 'The only way to correct this is for other people to become more active.' ... This all created a consciousness within the organization, so an effort was made by everybody to make other faces ... visible and that helped me (and the organization). But it's never an easy thing. There's always a little bit of tension there.

With time, leaders are likely to feel more ambivalent about their authority in women's organizations not only because of their own conflicting feelings and motivations about power, but because, as other members express their ambivalence, the leaders may feel alienated and unsupported.

\section{REPEATING TRADITIONAL BEHAVIOUR PATTERNS}

While organizational members may fear dominance by their leaders unjustly in some cases, in the absence of new models of leadership, women may well be capable of dominating behaviour with other women. Patterns of domination learned within the family, for example, are likely to be repeated in other contexts (Ianello 1992). Hierarchical 
structures pervade the culture of Bangladesh, like most world cultures. Besides being patriarchal, there are cultural models for female domination of other women, such as the behaviour of mothers-in-law towards their sons' wives (Maloney 1988).

The women I interviewed described a variety of experiences in their lives that potentially impacted on their approach to leadership and their consciousness about their own behaviour. They described their family backgrounds as largely hierarchical, with fathers in control like most cultures in the world. This was reinforced in their schools and work places. However, each woman also had experiences of taking responsibility in their families due to being the oldest child, a parent being sick, or being invited to participate in decision making. This required them to stand on their own at an early age, an unusual phenomenon for girls in Bangladesh. They were also exposed to non-traditional ideologies, including more equitable roles for women, from people in their lives involved in the Communist Party or other underground movements. Because I did not observe these leaders working in their organizations nor speak with their co-workers, I do not know how non-dictatorial they actually were in light of these or other influences.

Working as a leader and watching other leaders, I have found that women are often unconscious to the ways in which their own authority is exercised and to ways in which others abdicate authority despite everyone's commitment to consensus and participation. For example, one person remains the consistent group facilitator or the central recipient of information, or certain members always look to those with more experience or confidence to formulate decisions. In the case of the activist network:

When I ceased to be convenor, and I continued to have such a predominance over the way we interacted, operated, and proceeded, that's when it became clear to me, as well as to others, that something else had happened.

Many women's groups, in an effort to do away with traditional leadership, establish models where each member is to be equally responsible for leading and facilitating the group's functions. Yet leadership does not necessarily disappear merely by banishing leaders or rotating tasks and often becomes a covert hierarchy based on 'knowing the right person' or a core group of individuals with certain commonalties (Adamson, Briskin, McPhail 1989; Gandhi and Shah 1992). Such contradictory results were also revealed in the activist network:

You oppose a certain kind of hierarchy which is familiar and easy to reject and condemn, but then you reproduce other forms of hierarchy which are not so visible, which are couched less clearly in terms of oppression. Some of these hierarchies are formed not by any innate superior skills or knowledge or articulation, but by the fact that some people are more privileged in terms of being able to give time. The more you are with the process, the more you have command over the process, and that itself creates another kind of hierarchy. I am sure to the new person coming in ... the difference is not clear between the kind of hierarchy we condemn and what she sees.

This often unacknowledged disparity between what is professed and what is actually happening in the management of power within women's organizations also breeds ambivalence towards leadership. Many women's organizations have spent long painful periods stymied in the process of trying to bring these issues to light. Leaders and members need to honestly look at themselves and the impact of their personal and cultural histories to see and change their learned patterns around authority. This commitment to vigilance and mutual confrontation about sharing power must be on-going and requires a great deal of strength from the group.

\section{STRUGGLING FOR DOMINANCE BETWEEN THE LEADERS}

This contradiction between words and actions was also evident when it came to the relationships between women's organizations in Bangladesh. Bangladeshi analysts note a lack of coordination and shared ideology among women's groups. Women NGO workers outside the movement complained of this lack of unity and said, 'they are too busy fighting among each other instead of taking action' (Kirlels and Akhter 1989: 60). Some of the women who professed non-hierarchy were avidely competing for dominance with other organizations in the arena of women's movement leadership.

This competition sometimes took the form of personal attacks and criticism. In informal conversations 
with women organizers in Dhaka about women's organizations, they accused each other of being 'bullies' instead of participatory leaders, exploiting grassroots women through gaining income from their labour, wasting funding on unnecessary projects, not being sincere in their commitment to field work, professing to direct programmes that were really managed by their husbands, etc. ${ }^{4}$

The participants offered some explanations for this divisiveness:

I think the need to attack each other sometimes, unfortunately, comes from competing for male attention. Not from individual men, but by the male world. The world of public recognition in Bangladesh is still a very male-controlled, maledefined world.

Funding insecurity ... is the greatest thing which has really crushed our women's solidarity and collectiveness.

There is intolerance due to the incompetence of other women.

I think women are mean and jealous with each other because we are not confident ... Our insecurity is scattering us and making divide-andrule. That's why we are criticizing each other and making small blocs.

We have a lack of maturity. We are only recently coming out and organizing people. Men have been doing it for a long time. We just need that much experience and also that much privilege. We are all unprivileged and when we are unprivileged, we try to grab a little bit more.

Some of this competition appeared to have cultural roots in terms of replicating a systems of 'kinship hierarchies' in which elders and the wealthy bestow guardianship, usually economic, upon those in lesser positions who, in return, give their labour and allegiance (Maloney 1988; White 1992). As one woman explained:

(In both women's and men's organizations and) particularly in political parties, there is this projection of the kinship hierarchies that exist in families and clans. The way to ease relation-

4 Male NGO workers with whom I spoke made equally critical remarks about each other's work. However, their analysis of this ships is to clearly slot people as who is the older brother and who is the younger brother; similarly, in the women's movement, who is the older sister and who is the younger sister.

While I heard about and saw many instances of leaders seeking this kind of patronage from those with the most power in the NGO community (usually men), two of the women I interviewed resisted and resented the set-up, and also bore the brunt of their resistance:

It is my belief that we need change; but the older women in Bangladesh always want to dominate. They don't want to replace themselves with the younger women.

If, from the very beginning, we had accepted other women's organizations as older sisters, who have all the knowledge and the wisdom, I think things would have been easier... So ... we were not given the blessings, and we didn't seek them. I don't think there was ever any disrespect. It's just that we were much more wrapped up in wanting to do things differently.

It is no coincidence that women activists in Bangladesh experience divisions and mistrust of each other. Women's efforts to act with authority collectively are met with resistance by men. 'In a powerstructured relationship, the utmost aim of those in power positions is to prevent the oppressed from challenging the established order' (Eduards 1994: 183). It is not, she states, what men are doing to women but what they constrain women from doing in return. Women are permitted, even welcomed into the political arena if they do not press too strongly their own experience of oppression, shared by other women, which might translate into collective action. Yet, women's collective actions give them a wider range of experience, an identity as part of a group with common interests and a sense of agency. Patriarchal forces invest in denying women their collective agency because it is potentially dangerous to the power structure.

Men's efforts to keep women apart becomes internalized in the socialization process and is then expressed as hostility among women. If women can be kept divided from each other through in-

divisiveness centred almost entirely on funding competition. 
fighting and competition for scarce resources, guardianship, or male attention, then they have less energy and intention to unite and confront the systems created to oppress them.

Many women who assume leadership in the women's movement are caught in a self-defeating system of mutual mistrust and criticism. They undermine instead of support each other's assertions of authority on women's issues while trying to appear as a united front in the public sphere dominated by men. This conflict keeps them from unity.

\section{THE UNDERPINNING OF CLASS}

The question of class inequity has not been thoroughly addressed by most women's movements. In Bangladesh, with a female literacy rate of 19 per cent and with 85 per cent of the population of 108 million living at rural subsistence levels, the gap in experience between middle and upper class feminist leaders and the women they work to organize is very great (1991 statistics). Those with expertise in organizing are usually those with the most education, the most exposure to the professional world, and the most time to be active. These opportunities require a certain level of class privilege.

The women in this study were middle or upper class as well. They were all highly educated, most had practised management skills during campus politics or in previous employment positions, and had widened their perspectives through travel or study outside Bangladesh. Unlike some of their predecessors in women's organizing who never ventured from their urban homes, each of these women had either grown up in the rural areas or had done or were doing extensive work there. Still, they recognized their differences.

One thing I didn't do which people always say you should is merge with the people you are working with. I didn't think I will be able to merge; I'll stand out like a sore thumb, even though I wear a torn sari. I'm known there, married in that family. I will never be able to walk, move, do things like them. I decided the much more intelligent thing to do is to be myself and try to get to know them ... (The poor) see through you very quickly, so it's no use pretending.
Each leader acknowledged her privilege and its connection to the motivation for working with the poor:

I have some responsibility to the society because society has given me support. Of course, being a woman there are so many obstacles I have, but still ... being a woman in a privileged section of the society, I have recognized some problem and also I have recognized some way out it. I have some moral responsibility for that ... But I do not think of myself as a leader.

My Marxist training was always there. I wanted to work with the poor who have nothing. Let's see whether we can make them aware that they can be something if they want to. I took the poorest of the poor: women. They were the most neglected, the most exploited ...

Meanwhile, women in the slums and villages are bound to feel ambivalence toward the women who have come to 'help' them. They represent invaluable resources, education, organizing and sisterhood while also representing the dominant class which retains privileges the poorer women cannot achieve.

The women made some reference to being seen as 'wealthy, educated, Westernized women' by villagers and other colleagues in the women's movement, but did not analyse how their class privilege was playing out in their relationships with co-workers who represent a range of class backgrounds. The opportunities which come with class privilege can strengthen confidence and the ability to analyse and articulate which will play out in the power dynamics within organizations as well as in decisions about representing the organization in public. Much as gender oppression breeds a feeling of inferiority among women towards men, class oppression encourages working class women to defer to the authority of upper class women. Inevitably, class inequalities undermine egalitarian participation.

Women who try to address these issues in themselves and in their organizations will likely feel more ambivalent about the roles of leaders who come from privilege. The leaders in this study, for example, fluctuated between asserting leadership out of moral responsibility and stepping back from leadership to allow other women to come 
forward. One woman felt that, at least, a balance must be sought by women in positions of leadership responsibility:

One of the major reasons why women's organizations fail really often is because sometimes women can be quite free, capable, and efficient. All women are not. So if, in the moment, I can move, very soon I'll find that the people around me are men because they have moved with me. And I look around and I find the women way back. Just because you are efficient and capable, don't move that fast. Rather, drop back. Go slow so you can take the women with you.

\section{CONCLUSION}

Ambivalence about leadership and authority exist in both hierarchical and collective women's organizations in Bangladesh as elsewhere in the world, and results in internal and external conflicts. As women resist male organizational models of domination and subordination, they also experience a transition period which may include replicating traditional hierarchical patterns. This can result in the creation of covert hierarchies, resentment towards leaders by co-workers, and dominating behaviour on the part of leaders.
The pressure of the external world to conform to hierarchical modes of operation also reinforces traditional behaviours and lends to competition and divisiveness among women leaders. External resistance by men to women's collective strength and action also cultivates ambivalence among women and supports a lack of unity. While these struggles have their roots in gender inequity and its system of oppression, class inequity is also a factor which impacts women's work with each other.

To get women's organizations 'right for women in development', the leaders, staff, and memberships of these organizations must continually engage in open discussion and self-reflection on both personal and organizational levels. They must be willing to make changes in their behaviour where necessary to bridge the gap between their vision and the reality of women's empowerment. Identifying areas of ambivalence about leadership and authority is one place to start. This identification can enable clearer communication and more productive efforts in and among their organizations, and ultimately build a greater sense of solidarity. At the same time, feminist organizers must also credit themselves and each other for their daring and effective attempts to redefine and change organizational behaviour. These efforts are part of a process which is revolutionizing the nature of collective action.

\section{REFERENCES}

Adamson, Nancy, Briskin, L. and McPhail, M., 1989, Feminist Organizing for Change: The Contemporary Women's Movement in Canada, New York: Oxford University Press

Chernesky, Roslyn and Bombyk, M., 1988, 'Women's ways and effective management', AFFILIA Vol 3 No 1: 48-61

Eduards, Maud L., 1994, 'Women's agency and collective action', Women's Studies Int. Forum Vol 17 Nos 2/3: 181-86

Ferguson, Kathy E., 1984, The Feminist Case Against Bureaucracy, Philadelphia: Temple University Press

Gandhi, Nandita and Shah, N., 1992, The Issues at Stake, New Delhi: Kali for Women

Ianello, Kathleen P., 1992, Decisions Without Hierarchy: Feminist Intervention in Organization Theory and Practice, New York: Routledge

Jones, K. B., 1993, Compassionate Authority: Democracy and the Representation of Women, New York: Routledge

Kirlels, Edda and Akhter, S., 1989, 'Role and situation of women development workers in non governmental development organizations in Bangladesh', Bonn: Protestant Association for Cooperation in Development

Maloney, Clarence, 1988, Behaviour and Poverty in Bangladesh, Dhaka: The University Press

Mumtaz, Khawar and Shaheed, F., 1987, Women of Pakistan: Two Steps Forward, One Step Back? Lahore: Vanguard Books, (Pvt)

Saheli, 1985, Saheli the First Four Years, in Nandita Gandhi and N. Shah, 1992, The Issues at Stake, New Delhi: Kali for Women: 296

Siddiqui, Najma, 1992, 'Third World Feminism: An Alternative Paradigm for Development', ADAB, Grassroots: An Alternative Development Journal, Vol 1 No. 4: 27-31

White, Sarah, C., 1992, Arguing with the Crocodile: Gender and Class in Bangladesh, Dhaka: The University Press 